\title{
Tone Characteristics in Poems and Songs: A Comparative Study
}

\author{
V. V. Marchenko \\ National Technical University of Ukraine "Igor Sikorsky Kyiv Polytechnic Institute”, Kyiv, Ukraine \\ Corresponding author. E-mail: seonolut@gmail.com
}

Paper received 30.07.20; Accepted for publication 18.08.20.

\begin{abstract}
https://doi.org/10.31174/SEND-Ph2020-234VIII69-10
\end{abstract}
\begin{abstract}
In the present study we compare the components of speech and musical intonation and their integrated functioning within a song with a focus on tonal modifications. We ran an experimental phonetic research which comprised auditive and acoustic analyses followed by linguistic interpretation of the results. The research material included poems and songs created by setting the poetic texts to music. The degree of correspondence between speech intonation and musical intonation was quantified by identifying the pitch contour of a poem and then comparing this contour to the musical melodic contour to which the poem is set in a song. Overall, the pattern of the results indicates that despite the revealed differences, melodies in songs were found mainly congruent with the spoken pitch contour.
\end{abstract}

Keywords: speech, music, intonation, melody, tone, pitch.

Introduction. Numerous researches on speech-music relations prove that though different in many ways, speech and music definitely possess one common feature, which is intonation (D. Bolinger, R. Jackendoff). This idea encouraged us to carry out an experimental phonetic research during which we contrasted components of speech and music intonation and their integrated functioning within a song. Throughout the research we focus on the songs created by setting the poetic texts to music, since we believe that within a song its verbal and music components either correlate or, on the contrary, disaccord, thus revealing both common and distinctive features of language and music.

The theoretical and ensuing experimental phonetic research revealed both common and distinctive features of speech and music and the objective of the paper is to present the ways speech and music correlate within a song with the focus on tonal characteristics of both domains.

Tone in speech and music: A brief overview of relevant studies. The deep affinity of speech and music might be supported by the fact that, firstly, speech and musical intonation are basically the branches of a single sound flow [1, p. 8], and, secondly, that speech and vocal music operate with a common sound material through which an individual expresses their inner emotional state, the reaction and attitude to the outside world. All these may indicate that speech and music are processed by common brain center and have common auditory channels [8, p. 17].

Although speech and music share some auditory and acoustic features (melody, frequency, pitch, intensity, timbre, duration, rhythm), there is a significant difference between the two: while in speech the sound is uncertain in height, the increase and decrease in it are approximate, in music sound is not only clearly defined, but also the tones are mutually coordinated, complying with the mode $[5, \mathrm{p}$. 34].

For further analysis it is necessary to clarify the definition of intonation in linguistics and musicology. In linguistics, intonation refers to the complex set of such prosodic elements as melody, rhythm, intensity, tempo, timbre and logical stress, which express syntactic meanings and categories, as well as expressive and emotional connotations [4, p. 29].

In musicology, broadly speaking, the term "intonation" refers to the pitch organization of musical sounds in their sequence, that is, the sounding of each tone in terms of pitch level, loudness and timbre, as well as the manner of musical expression, which is a complex of characteristic features of the musical form (high-altitude, rhythmic, articulation, etc.) that determine its semantics or emotional and semantic significance for recipients [8]. In the narrow sense, both linguists and musicologists determine the intonation as pitch variations.

Thus, intonation is known to be a complex unity of speech melody, utterance stress, rhythm, tempo, pausation, loudness and voice timbre which enables he speaker to express their emotions, feelings, thoughts and attitudes.

Melody is regarded as leading component of the intonation of both speech and music [6, p. 24-25] and intonation, also defined as the variation of the pitch of the voice, basically reduces to its one component - melody.

Both in linguistics and musicology melody is viewed as a subsystem of intonation which embraces the pitch level, the pitch range, the tonal interval, the rate of pitch variations and the rate of tone movement changes $[6, \mathrm{p}$. 102]. Yet in music melody additionally comprises mode and harmony [4, p. 10-11].

All intonation components are actualised in intonation group, which is the experimental unit of our research. Emotional and pragmatic potential of each intonation group in a song is conveyed by a harmonious synthesis of intonation components, among which a crucial role is played by terminal tone as a bearer of specific meanings, ideas, messages, mood, feelings and emotions.

In musicology, a musical tone is a steady sound, which is characterized most frequently by its pitch, but it also includes timbre, duration, and even intensity (the dynamic of the sound) [8, p. 4].

In our research we distinguish between simple tones, (i.e. the tone which does not change its direction throughout its pronunciation), e.g.: low/mid-low/mid-high/high falling tone or low/mid-low/mid-high/high rising tone) and compound tones (i.e. the tone which movement is changed throughout its duration), e.g.: the falling-rising tone, the rising-falling tone, the rising-falling-rising tone, the falling-rising-falling tone) [6, p. 123-124]. The comparative study demonstrates the way terminal tones are represented by means of adding music to verbal component.

Methods of research. The experimental phonetic re- 
search involved auditive (perceptive) and acoustic (instrumental) analyses followed up by linguistic interpretation of the data obtained. Thus, the experimental phonetic research comprised the following steps:

1. Auditive analysis was performed by two groups of auditors: At the first stage of auditive analysis phoneticians listened to poetic fragments and determined the kind of pre-head, head, terminal tone, tonal range, tonal interval, rhythmic structure, tempo, loudness, pause and timbre. At the second stage of auditive analysis the nature of the intonation components, shared by both speech and music, was also determined by musicians from their perspective at the final stage of auditive analysis. Additionally, musicians determined some exclusively music qualities such as mode, tonality, and harmony.

2. During the acoustic analysis certain experimental fragments in wav format underwent acoustic processing by means of such software as SpectraPLUS, WaveLab, CoolEditPro, PRAAT. The software helped to detect and measure such acoustic qualities as fundamental frequency, intensity and duration.

3. The data obtained during both auditive and acoustic analyses were subjected to linguistic interpretation, i.e. comparison of the intonation qualities of speech and music. Such a contrasting helped to detect intonation qualities common for both domains as well as some discrepancies between them.

Experimental material included 10796 intonation groups from 162 songs which were created by adding music to the already existing poem.

Results and discussion. The experimental phonetic reserch revealed a variety of ways terminal tones of poetic works can be reproduced in songs. It also indicated that pitch variations within intonation groups in a poem and in a song might differ, yet the characteristics of terminal tone tend to remain the same. Let us consider the following examples in which we compare poems from T.S. Eliot's “Old Possum's Book of Practical Cats" and same-name songs from Andrew Lloyd Webber's musical Cats.

The first fragment tells about successful and glorious past of Gus the actor, which is marked by the use of relevant emotionally-colored vocabulary in resonance with the appropriate prosodic pattern:

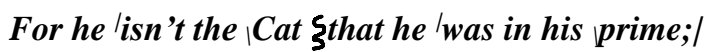 Though his Iname was $\uparrow$ quite famous, ģe says, igु its time.\|

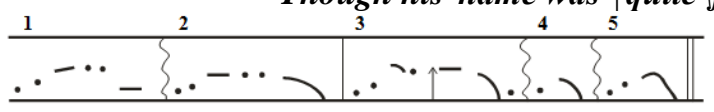

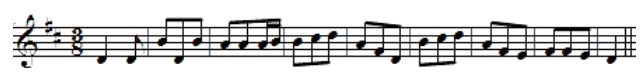

The high level of the emotional-and-pragmatic potential of this fragment is ensured by falling terminal tones, functioning on meaningful lexical units (Cat, prime, famous, time). In the first intonation group (For he lisn't the (Cat), the movement of the falling terminal tone starts in the low zone of the mid register and finishes in the high zone of the low register, which in combination with reduced loudness and legato-like rhythm makes the fragment sound fleeting, melancholic, heart-broken and sad. This mood is intensified in the second intonation group

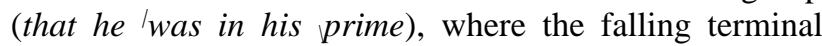
tone, implemented on the meaningful word prime, acquires a low rate of tone movement change and reduced loudness. Further enhancement of Gus's fading glory occurs in the third intonation group (Though his Iname was $\uparrow$ quite famous) through the use of broken descending stepping scale (special rise on the word $\uparrow$ quite), falling terminal tone on famous, regular rhythm, moderate tempo and moderate loudness.

In the song a story of Gus's acting talent is enhanced by $\mathrm{D}$-major key actualized in the narrowed pitch range, legato-like rhythm and pitch variations, giving the fragment a wave-like melodic contour. It is also important to emphasize the role of musical instruments in the communication of this work's main idea and emotions: a part of several violins and alto tunes into the melodic contour on the words prime, famous, time.

Another example demonstrates the integrated functioning of law falling tone and gradually descending sliding scale:

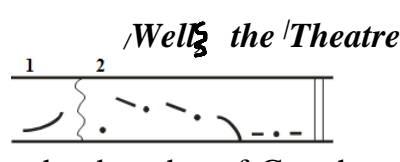

The utterance summarizes the thoughts of Gus the actor, who recalls the good old days with sadness and nostalgia and is quite critical of contemporary theater and actors who, in his opinion, «do not get trained as we did in the days when Victoria reigned». Melancholic mood of the first intonation group ( $/ W e l l$ ) is delivered by mid-low rising terminal tone, implemented with decelerated tempo by means of prolonged rendering of a word well. These prosodic parameters together with moderate loudness give this utterance some positive, light, but sorrowful timbre pattern and tune the listener in the perception of some critical information.

Such mood is considerably reinforced in the second intonation group (the $\mid$ Theatre's ${ }^{\mid}$certainly 'not $\mid$what it $\mid$was), which deliver the speaker's critical attitude towards the modern theater by means of gradually descending sliding

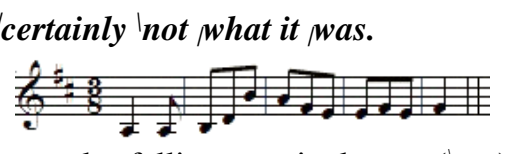

scale, falling terminal tone ('not), which starts its movement on mid-high pitch and finishes on low pitch, as well as the high rate of tone movement changes, which makes the utterance sound categorically. All described above in combination with loudness modifications from increased (on the word Theatre) to low (in the tail |what it $\mid$ was) convey discouragement and frustration.

The degree of emotionality of the utterance is amplified by the addition of a musical component to a poetic work. The first intonation group (/Well) is performed one octave lower than the second intonation group (the 'Theatre's I certainly 'not |what it |was) and thus acquires the intonation of sigh. The second intonation group is performed at a higher pitch with tone increase on the word Theater, which is consistent with the prosody of the poetic fragment. Such modifications of pitch combined with 
moderate tempo and a tense, trembling and dramatic timbre illustrates the transience and brevity of human life and the Gus's extraordinary longing for the past, for the theater, his desire to turn back time, to catch up with youth that unavoidably leaves him.

Correlation of tempo, rhythm, loudness and tonal variations can be illustrated by the following example:

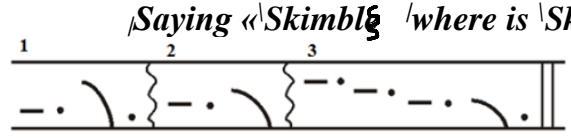

Skimbleshanks, another character from Cats the musical, is a figure of great importance in the train's operation: it will not leave without him. Therefore when the train is about to depart but Skimble is nowhere around, passengers and crew are sticken with panic. The growth of tension, edginess and anxiety is conveyed primarily through acselerated tempo, loudness varying from increased to moderate with a tendency to further decrease, the beginning of intonation groups on different pitch levels, gradual reduction of pitch range from broad in the first intonation group to mid in the third one, checked heads and specific features of each terminal tone.

High rate of movement of high falling terminal tone in the first intonation group (|Saying «Skimble), its wide pitch range, rising-falling melodic cintour, increased loudness on 'Skimble together with acselerated tempo indicate the speaker's emotional excitement and anxiety. In the second intonation group ('where is 'Skimble) nervousness and excitement keep on increasing by means of checked head and mid-high falling terminal tone with avarage rate of tone movement change. The same mood is

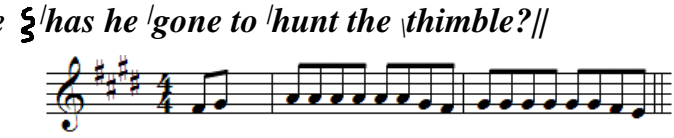

preserved in the third intonation group ('has he Igone to hunt the thimble?) with the help of moderate loudness, regular rhythm, acselerated tempo, gradually descending stepping scale, and low falling terminal tone on thimble with avarage rate of tone movement change.

As we can see from musical notation above, the song mirrors the melodic contour of a poetic fragment, reproducing the falling terminal tones by means of the downward pitch movement. Comparison of poetic and musical fragments shows the identity of their tempo-rhythmic characteristics: the accelerated tempo and regular rhythm of a poetic work coincide with the allegretto vivace tempo and the simple rhythm of its musical variant. The parts with increased loudness in the poetic fragment get similar prosodic pattern in the musical version by being performed very loudly, practically in an outcry (ff-fortissimo indication on the music sheet).

Equally interesting is the functioning of level (static) tone, i.e. a tone produced with an unchanging pitch level of the tone movement, and its reproduction in singing. Let us consider the following example:

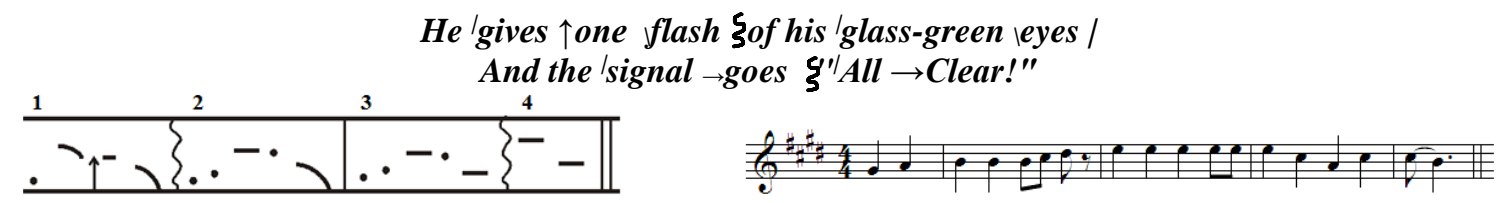

In the third (And the | signal $\rightarrow$ goes) and fourth $\left({ }^{\prime}\right.$ All $\rightarrow$ Clear!) intonation groups the emotions and semantics are conveyed through level terminal tones realized on mid-low and mid-high pitch respectively. Here level terminal tones certainly bear onomatopoeic meaning and imitate the train starting signal.

While setting this poem to music level tone is preserved and conveyed by (a) slurring $(\neg)$, i.e.

\section{The $\mid$ Rum `Tum /Tugger Şis a 'Curious $\mid$ Cat ||}

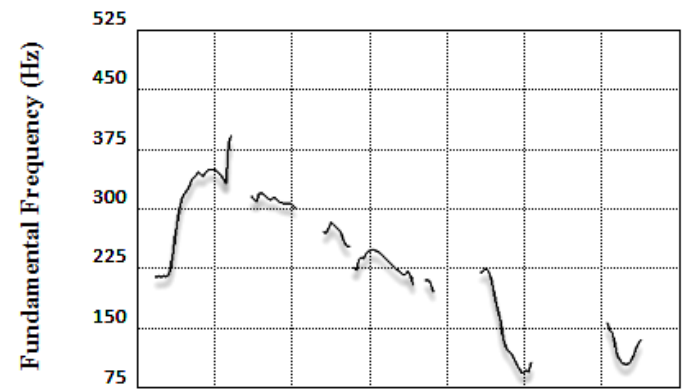

Fig. 1 Graphic interpretation of the fundamental frequency of the poetic fragment "The Rum Tum Tugger is a Curious Cat"

As is seen from Figure 1 the fundamental frequency in the first intonation group (The ${ }^{\mid}$Rum ${ }^{\circ}$ Tum Tugger) is located on the first stressed syllable and the tonal maximum is realised in the high zone, which shows speaker's intention to draw listener's attention to the prolonged performance of the combined notes with as much legato as possible, and (b) augmentation of the quarter note $B\left(\rho^{\bullet}\right)$ by half of its original value.

The acoustic processing of poetic and music fragments confirmed the compliance in the localization and variation of fundamental frequency maximum indexes, which is distinctly demonstrated in Figure 1 and Figure 2.

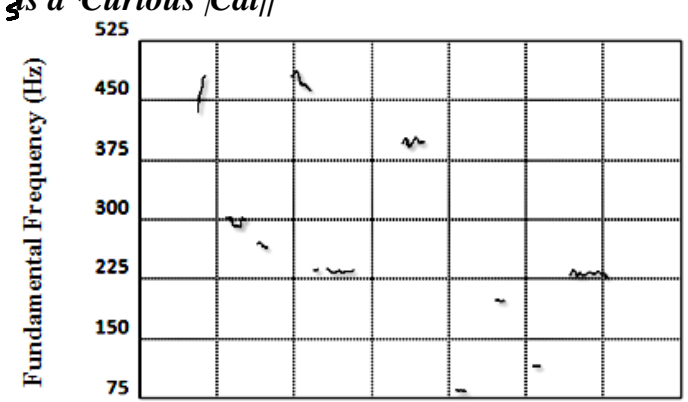

Fig. 2 Graphic interpretation of the fundamental frequency of the song fragment "The Rum Tum Tugger is a Curious Cat"

event.

Graphic interpretation of fundamental frequency in musical variant (Figure 2) shows the falling tone direction, identical to the one in the poetic fragment, and tone maximum allocation on the first stressed syllable in 
high zone.

The acoustic analysis also showed some differences between speech and music intonation. The main discrepancies lie in the variation of fundamental frequency localization within one and the same intonation group. For instance, in the first intonation group of the poetic fragment $O$ say, can you see, by the dawn's early light, What so proudly we hailed at the twilight's last gleaming? (Figure

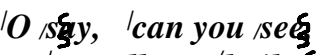
What so proudly we'haile@s

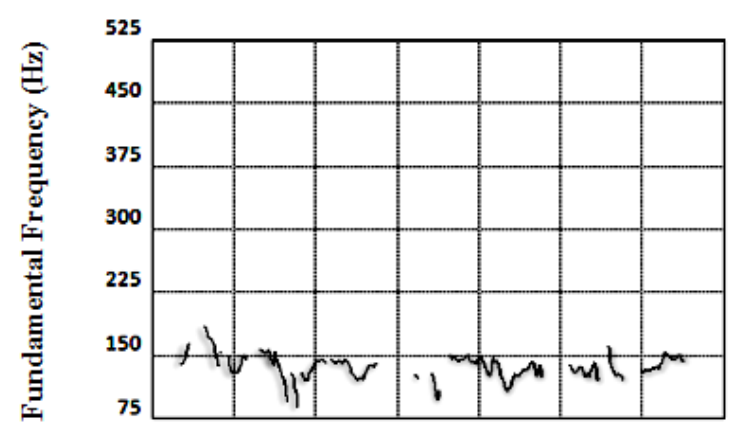

Fig. 3 Graphic interpretation of the fundamental frequency of the poetic fragment "O say, can you see, by the dawn's early light, what so proudly we hailed at the twilight's last gleaming?"

However, in song variant of this fragment (Figure 4) fundamental frequency maximum is registered on the prehead (by the) of the third intonation group, thus emphasizing the preposition by and article the which have no emotional meaning in the poetic variant. The specified lexical units are singled out by the rising pitch movement in the previous syntagm ('can you see $)$ and high vocal potential of a-glide of [aI] diphthong, which is actualized in high maximum zone and gives suggestive potential to the whole fragment.

Conclusions. The presented comparative research showed that speech and music thoroughly correlate in
3) the fundamental frequency maximum allocates on the nuclear syllabic element in mid-low zone of tonal maximum. Here localization of fundamental frequency on say in combination with narrowed tonal range, increased loudness and accelerated tempo shows the speaker's interest in the listener's opinion and desire to receive the answer to his question at the earliest moment.

\section{by the Idawn's |early light, | \\ at the 'twilight's 'last'gleaming?||}

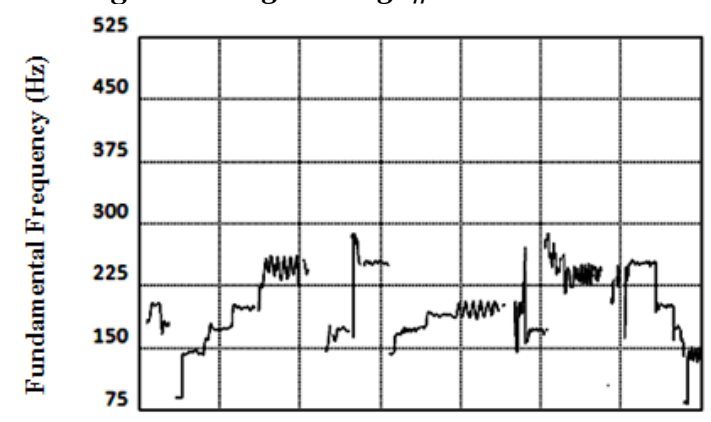

Fig. 4 Graphic interpretation of the fundamental frequency of the song fragment "O say, can you see, by the dawn's early light, what so proudly we hailed at the twilight's last gleaming?"

prosody, possessing some common auditive and acoustic features, among which tonal characteristics prove to be the leading ones in the conveyance of thoughts, emotions and attitudes. The paper proves that meanings conveyed by terminal tones in poems are mainly successfully reproduced by music means in songs created by setting the poems to music.

We assume that the further research on speech-music relations should be aimed at revealing prosodic commonalities and differences through studying songs of different genres, sub-genres and styles.

\section{ЛИТЕРАТУРА}

1. Асафьев Б. В. Речевая интонация. М.: Музыка. 1965. 250 c.

5. Bolinger D. L. Intonation and Its Parts. Stanford: Stanford University Press, 1986. $421 \mathrm{p}$.

2. Калита А. А. Фонетичні засоби актуалізації смислу англійського емоційного висловлювання. К.: Видавничий центр КДЛУ. 2001. 351 с.

3. Мазель Л. А. О мелодии. М.: Государственное музыкальное издательство, $1992.300 \mathrm{c}$.

4. Ручьевская Е. А. Слово и музыка. Л.: Музгиз, 1960. 56 с.

6. Crystall D. Prosodic Systems and Intonation in English. Cambridge: Cambridge University Press, 1969. 392 p.

7. Roederer J. G. The Physics and Psychophysics of Music: An Introduction. Springer, 2008. 228 p.

8. Vincent M. L. Music and language interrelations: towards an evolutionary, semiotic and compositional perspective. Toronto, Ontario, 2010. $131 \mathrm{p}$.

\section{REFERENCES}

1. Asafiev B. V. Speech Intonation. Moscow: Music, 1985. 134 p.

2. Kalyta A. A. Phonetic means of the actualization of emotional utterance meaning. Kyiv: Publishing Centre KDLU, 2001. $351 \mathrm{p}$.
3. Mazel L. A. About Melody. M.: Gosudarstvennoe muzykalnoe izdatelstvo, 1992. $300 \mathrm{p}$.

4. Ruchievskaia E. A. A Word and Music. Moscow: Muzgiz, $1980.56 \mathrm{p}$.

perspective. Toronto, Ontario, 2010. 131 p. 